\title{
The Effect of Attendance on Academic Performance
}

\author{
Rudina Guleker \\ The Foundation Program Department of English, Qatar University, Doha, Qatar \\ Email: rudinak@yahoo.com \\ Julinda Keci \\ Civil Engineering Department, EPOKA University, Albania \\ Email: jkeci@epoka.edu.al
}

Doi:10.5901/mjss.2014.v5n23p961

\begin{abstract}
Faculty in higher education institutions oftentimes follow different attendance practices and policies: some make it compulsory and count toward the final grade while others do not. Even when attendance is not compulsory, many faculty believe in its positive effect in academic performance. In this article a summary of the latest studies on attendance and academic performance will be given along with a deeper analysis of this relation in Albanian context. Data are collected from two courses in the civil engineering department of a private university taught by the same lecturer during 2009-2012. The results of the study are discussed in the light of the attendance policy enforced in today's Albanian higher education institutions.
\end{abstract}

Keywords: Attendance; Academic Performance; Higher Education; Albania;

\section{Introduction}

Student attendance is an important issue in today's' higher education. Many universities have compulsory attendance policies, while others refrain from making it as such. Despite the different policies, there seems to be a consensus among the professors about the positive effect of attendance in academic performance. Not attending classes is seen as one of the reasons for academic failure. The recent developments in information and technology require a re-evaluation of the traditional method of study and the belief that undergraduate students benefit from class attendance should be tested. Moreover the presence of the new study methods based on distance learning requires a further analysis and discussion on the physical course attendance. In the last decade, a number of studies have investigated the relation between class attendance and academic performance reaching to the conclusion that there exists a positive correlation between these two (Durden and Ellis (1995), Devadoss and Foltz (1996), Marburger (2001), Kirby and McElroy (2003)).

Along with the direct investigation between these two variables, other problems investigated were related to the effect of the secondary variables such as intrinsic motivation and interest on the first correlation.

This study aims at looking into the effect of attendance in academic performance using data collected over years from two bachelor courses from a civil engineering program in a private university in Tirana. The study of different aspects and contexts of this issue, would positively affect higher education policies.

The establishment of a correlation between attendance and performance would assist professors applying different policies and it will have a wider effect in informing the policy makers in higher educational field in Albania.

\section{Why Students do not Attend Classes?}

Course attendance, especially lecture attendance in universities, has been a problem in many countries in the world. In a study conducted in three well-known American universities Romer found that the overall non attendance percentage reached 33\% and that it was higher in courses that were remotely related to math. (Romer, 1993) In another study done at the University College in Dublin, Purcell (Purcell, 2007) determined that the second and third year civil engineering student attendance was at the level of $68 \%$, while in Finlad Kolari (Kolari, 2008) found that the attendance of Finnish civil engineering students was only at the level of $40 \%$. Ditcher \& Hunter (Ditcher \& Hunter, 2004) concluded that some students, whom they would call instrumental students, do not value the process, but only the result. This is not a new phenomena and it is indeed increasing. These students, who focus on the diploma and not on the added value that 
higher education brings, are probably not the best course attendees. Despite the absence of statistics in Albania, the international trend shows that the number of students who work part-time during their undergraduate studies has increased (O'Dwayer, 2011). Kirby and McElroy (Kirby and McElroy, 2003) studied 368 economics students and concluded that the working hours and the commute distance were among the most important factors in course attendance. The increasing number of the universities out of Tirana city center makes the latter an interesting factor for the Albanian context. At the same time, studies have shown that when the lectures are only a presentation of the information in the textbook, not attending has little effect on performance. (Buckles and McMahon, 1971, from Gendron and Pieper, 2005). With the recent development in the way information is transmitted, students have access to multiple sources through which they can get the required information oftentimes in a more suitable way for their preferences and lifestyle. So if we would like to keep our students in our classrooms and lecture halls, we need to think about the added value.

\section{Attendance and Performance}

A number of research studies suggest a correlation between attendance and performance in college. The first attempts to study this relationship have been from Robert Schmidt (Robert Schmidt, 1983) who concluded that the time spent in class was the primary factor to effect student performance followed by the time spent in individual study. The last factor was the time spent in exam preparation. Marburger (Marburger, 2001) in a study with 60 students in a microeconomics course, observed the percentage of the correct answers belonging to the material covered in non attended lectures. He concluded that the students were more likely to give wrong answers to these types of questions compared to the questions belonging to the lectures they attended.

Studies on this topic have been done in a wide array of programs from science to social studies with similar conclusions. Callahan (Callahan, 1990) found a positive correlation between attendance and performance in a math course; Park \& Kerr (Park \& Kerr, 1990) in a banking policy course; Van Blerkom (Van Blerkom, 1992) and Shimoff \& Catania (Shimoff \& Catania, 2001) in an introductory course in psychology. A problem mentioned extensively in these studies is the problem of the effect of the indirect variables on attendance. Eliminating the effect of intrinsic motivation, GPA, and college preparedness has been proven difficult. Although attendance has been seen as an important factor in performance, GPA and college preparedness before entering university have had a greater effect on performance (Devadoss and Foltz, 1996). Johnson (Johnson, 2002) found a strong positive correlation between dedication and performance. On the other hand in Devadoss and Foltz study it was concluded that if GPA and motivation is controlled, students who better attended courses had a higher average of two grades compared to the ones who had a $50 \%$ or lower attendance. Durden and Ellis (Durden and Ellis, 1995) in their study with 346 economics students showed that attendance remained important when the other variables mentioned in the literature such as motivation and preparedness were controlled for. As a result, although it is true that dedicated, motivated and high GPA students are likely to attend more and achieve higher results, the correlation between attendance and performance can be seen as a determining factor for motivation and further better performance. This study is part of the realm of studies that look into this relationship. The matter whether the absences are acceptable and which amount is considered safe has been the subject of other studies which concluded that there is a threshold and if exceeded, it has meaningful negative effects on student performance. Durden \&Ellis (Durden \&Ellis, 1995) showed that a small number of absences do not really affect performance whereas when it exceeded 4 absences the performance was affected negatively. Likewise Silvestri (Silvestri, 2003) in a study with teaching majors found a weak negative correlation between the number of absences and the course grades when these absences were less than three whereas for four or more absences the negative correlation was strong.

Van Blerkom (Van Blerkom, 1992) reports that sophomores tend to be more absent than the freshmen and the seniors. In addition, in his study he concludes that gender is not a meaningful factor in this correlation.

Colby (Colby, 2004) analyzed the effect of attendance in the performance of 178 freshmen students in an undergraduate program. The results showed a positive correlation between these variables. He also contributed two attendance rules: the $70 \%$ and the $80 \%$ rule. The former states that if a student does not attend at least $70 \%$ of the classes he/she has a probability of two in three to receive a failing mark and a probability of 4 in 5 to have low grades. The $80 \%$ rule stated that if a student does not attend at least $80 \%$ of the courses, the probability to get failing grades is $50 \%$, whereas the probability not to get high grades is 2 in 3 . 


\section{Methodology}

This study uses data from two undergraduate courses in Civil Engineering in a private university in Tirana: Engineering Economy (CE: 221) and Construction Management (CE: 312). The data has been collected in a span of three academic years: 2009-2010, 2010-2011, 2011-2012, and the courses have been taught by the same faculty. The first course was offered in the fall semester whereas the second in the spring semester. To record attendance, attendance sheets signed by students have been entered and saved in the data management system of the university. The system gives the attendance records in percentage. Performance evaluation was done through the midterm and final exam giving the students a grade from four to ten. The university implements a partly compulsory attendance policy according to which the student can not take the final exam unless he/she attends at least $50 \%$ of the course. In this case, some students were exempt from the attendance requirement because they were taking the course for the second time for GPA purposes. Many universities in Albania have a similar attendance policy for seminar classes. Considering the fact that this particular university does not make a distinction between seminar and lecture classes, this compulsory attendance policy seems justified and in accordance with Albanian context. Despite the compulsory attendance policy, 13 students out of 107 (12\%) could not sit the final exam because of attending less than 50\%. Therefore, only 94 students had a valid final grade to be used for the study.

The students were classified in three groups based on the percentage of attendance:

- Students with good attendance( over $85 \%$ );

- $\quad$ Students with acceptable attendance.( $70 \%$ - $85 \%$ );

- Students with poor attendance (50\%-70\%)

For this study, student performance was divided in three categories:

- Successful: over eight

- Passing: six and seven

- Failing: under six.

The attendance percentages will be analysed using Colby's rules (Colby, 2004). The $70 \%$ rule equals to 4 weeks of non attendance considering the courses were taught 3 hours a week for 14 weeks. The $85 \%$ case with 2 weeks of absences will also be discussed and the probabilities to get successful and failing grades will be discussed for both cases.

The hypothesis are below:

- A positive correlation is predicted between attendance and performance.

- The $70 \%$ rule will be valid for the Albanian context.

\section{Results and Discussions}

Among 94 valid cases, 42 students were enrolled in CE 221 and 42 in CE 312. The data were analysed as 94 cases based on the previous studies done both in one course and multiple courses. The similarity in course content and the fact that the same faculty taught both courses also were other factors that brought these data together. In addition based on the data, there was no significant difference in each course's attendance, being respectively $79 \%$ and $81 \%$. This small difference may also be explained with the difference in the semester the courses were offered: CE 221 fall and CE 312 spring semester. The literature has showed that spring courses are attended more that the fall and winter ones.

Table 1 gives a general description of attendance and performance for the participants in the study showing the average of attendance as $79.89 \%$. This number is higher than the ones mentioned in the literature. This finding can be explained by the fact that in this context there was a compulsory attendance policy in place and it has greatly affected the average attendance of the students. In fact, all the students with less than $50 \%$ attendance have been repeaters who were excluded from the mandatory attendance rule. Therefore it can be deduced that had there not been an attendance policy in place, the average attendance would have been much lower. The high attendance average is also shown in table 2 where only 22 cases of poor attendance are observed.

Regarding the first hypothesis, a further analysis showed that there was a strong correlation between the two variables, attendance and performance $(r=0.65, p<0.01)$. 
Table 1. General Description

\begin{tabular}{|l|c|c|c|c|c|}
\hline & N & Min. & Max. & Average & Std. Deviation \\
\hline Attendance Percentage & 94 & 27.51 & 100.00 & 79.8959 & 17.66983 \\
Performance in Grades & 94 & 4 & 10 & 7.33 & 2.008 \\
\hline
\end{tabular}

Table 2. Student classification according to attendance categories

\begin{tabular}{|l|c|c|c|}
\hline Attendance & $\mathrm{N}$ & Average & Standard Deviation \\
\hline good (85-100) & 48 & 93.0017 & 5.16479 \\
acceptable (70-85) & 25 & 77.78 & 4.35130 \\
poor (<70) & 21 & 53.0605 & 13.81906 \\
\hline
\end{tabular}

Figure 1 shows that there is no big gap between the attendance of the students with successful and passing grades but there is a noticeable gap between the attendance of the above mentioned groups with the students with poor academic performance. This reasult is also shown through the scatterplot diagram.

The results can be justified via the attendance threshold hypothesis mentioned in literature namely there is a limit of absences beyond which the correlation between the grade and attendance becomes strong. Not passing the threshold may cause the correlation to be weak.

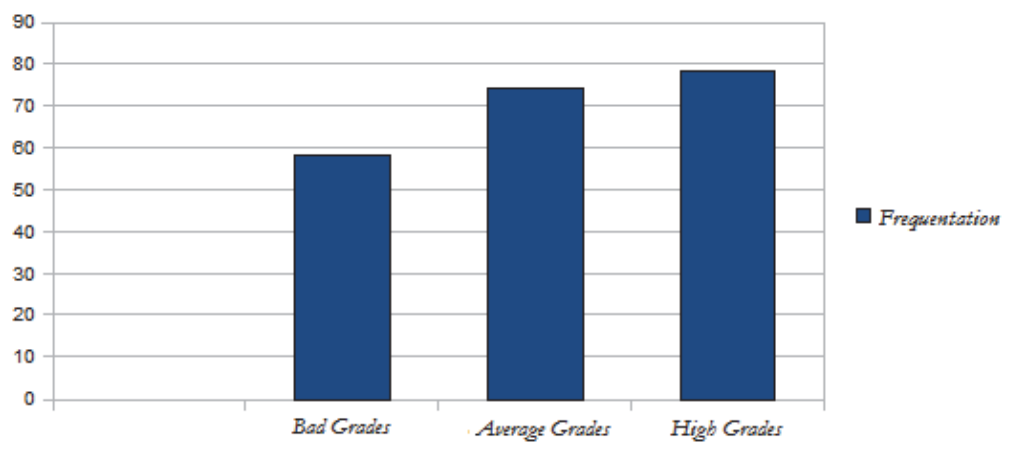

Figure 1. Attendance according to performance categories

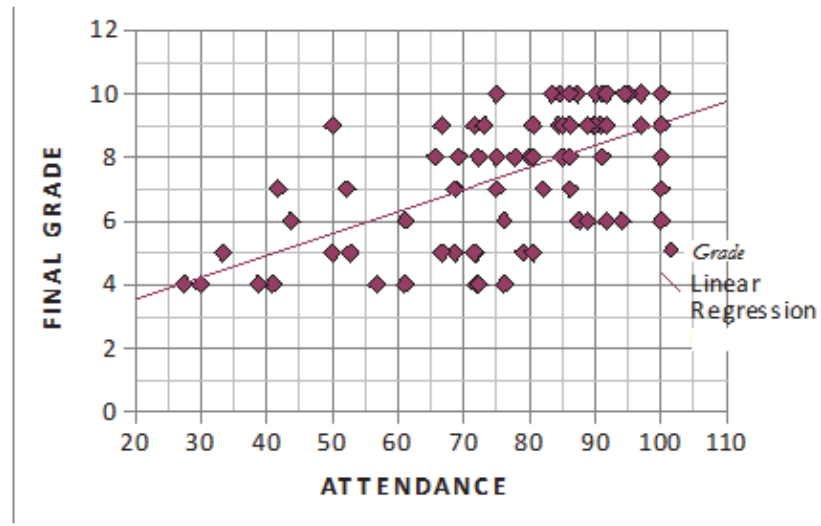

Figure 2. Scatterplot of attendance and performance

Regarding the second hypothesis, the analysis of 21 poor attendance cases shows that Colby's $70 \%$ rule is perfectly true for this case. There were 14 cases of failing grades in the poor attendance category which makes the probability 2 in 3 . On the other hand, 4 in 5.5 students ( 4 in 5 according to Colby) have the possibility of not receiving a successful grade. In 
other words, students that miss 4 weeks have $66.7 \%$ probability to receive a failing grade and $80 \%$ are likely not to get a successful grade. A similar result is also confirmed by Newman-Ford (2008). The other case examined in this study is the attendance at less than $85 \%$ level where we find students with an acceptable attendance. 48 cases were analysed in this category. The probability of these students to get failing grades was $37,5 \%$ (3 in 8), whereas the probability not to get successful grades was $58.3 \%$ (7 in 12). For the $80 \%$ category Colby found $50 \%$ and $66.7 \%$ respectively. Newman-Ford (Newman-Ford, 2008) found $25 \%$ probability of receiving a failing grade and $75 \%$ chance of non receiving successful grades. The $85 \%$ is a new rule so there are no matches in literature to compare. These results are shown in Figure 3

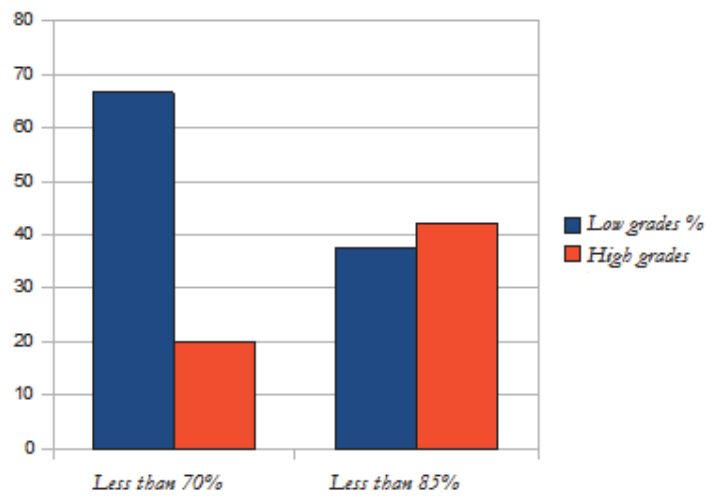

Figure 3. Student probability of receiving failing and successful grades according to attendance

\section{Limitations and Conclusions}

Although a correlation between attendance and performance was found in this study, it is not a cause and effect relationship. The data show that there are students with good attendance standing who received failing grades. The $85 \%$ rule showed that there are students predisposed to receive failing grades regardless the attendance. Nevertheless, the rules presented in this study suggest that the higher the attendance is, the lower the probability of receiving failing grades appears to be as well. The relatively small number of cases can be viewed as a limitation for the study. The analysis of only two courses made impossible the possibility of comparing results between departments. The narrow scope of the present study leaving out some factors that influence attendance can be viewed as another limitation. The attendance data could have been completed with questionnaires to gain a deeper understanding on the reasons of non attendance. This might be a topic for further research. Inclusion of public universities would have had a huge value in generalizing the results.

Despite all the limitations, the study reached to the conclusion that the compulsory attendance policy using a threshold would be in students's best interest and it will serve well the whole educational process. As presented above, a not attendance of $30 \%$ or greater increases the chance for failing grades and decreases the chance for successful ones. Therefore, student attendance shouldn't be far from this number. Of course the interactive methods of content delivery and overall course structure will keep students in auditoriums and will make compulsory attendance policy less needed.

\section{References}

Colby, J. (2004) 'Attendance and Attainment'. 5th Annual Conference of the Information and Computer Sciences - Learning and Teaching Support Network (ICS-LTSN), 31 August-2 September, University of Ulster.

Robert M. Schmidt (1983), "Who Maximizes What? A Study in Student Time A llocation", American Economic Review 73 (No. 2, 1983): 23-28.

Devadoss, S., and Foltz, J. (1996), "Evaluation of factors influencing student class attendance and performance", American Journal of Agricultural Economics, vol. 78(3), 499-507

Romer, D. (1993), "Do students go to class? Should they?", Journal of Economic Perspectives, vol.7(3), pp. 167-74

Durden G. and Ellis L., (1995), "The Effects of Attendance on Student Learning in Principles of Economics", American Economic Review, Vol. 85, (Summer),

Silvestri, L. (2003), "The effects of attendance on undergraduate methods course grades",Education 123(3), 483-486

Marburger, D. R. (2001), "Absenteeism and Undergraduate Exam Perfor- mance", Journal of Economic Education, p. 99-110

Van Blerkom, Malcolm L. (1992) "Class attendance in undergraduate courses." The Journal of Psychology, 126(5): 487-494 
Shimoff, Eliot and A. Charles Catania (2001), "Effects of Recording Attendance on Grades in Introductory Psychology." Teaching of Psychology, 28(3): 192-195

Buckles, Stephen G. and Marshall E. McMahon (1971) "Further Evidence on the Value of Lecture in Elementary Economics", Journal of Economic Education, 2(2): 138-141

Kirby A. and McElroy B. (2003) "The Effect of Attendance on Grade for First Year Economics Students in University College Cork", The Economic and Social Review, 34(3), pp. 311-326

Purcell P. (2007). Engineering student attendance at lectures: effect on examination performance, Proceedings of the International Conference on Engineering and Education, Coimbra, Portugal, 2007. Mare nga: http://icee2007.dei.uc.pt/proceedings/ papers/107.pdf

Park, K. H. and P. M. Kerr (1990) "Determinants of Academic Performance: a Multinomial Logit Approach." Journal of Economic Education, 21(2), pp. 101-11.

S. Kolari, C. Savander-Ranne and E-L. Viskari. Learning needs time and effort: a time-use study of engineering students, European Journal of Engineerng Education, Vol. 33, No. 5/6, 2008, pp. 483-498.

O'Dwayer, A.(2011). Does a Link Exist Between Examination Performance and Lecture Attendance for First Year Engineering Students. Mare nga: http://arrow.dit.ie/cgi/viewcontent.cgi?article=1172\&context=engscheleart\&sei-redir.

Gendron P., and Pieper P., (2005), "Does Attendance Matter? Evidence from an Ontario ITAL", Mare nga: http://economics.ca/ 2005/papers/0483.pdf

Newman-Ford, L., Fitzgibbon, L., Lloy, S., and Thomas, S., "A large-scale investigation into the relationship between attendance and attainment: a study using an innovative, electronic attendance monitoring system", Studies in Higher Education, Vol. 33, No. 6, December 2008, 699-717. 